\title{
Damage evolution in cement mortar due to erosion of sulphate
}

\author{
Jian-kang Chen ${ }^{\mathrm{a}, *}$, Min-qiang Jiang ${ }^{\mathrm{b}}$, Jue $\mathrm{Zhu}^{\mathrm{a}}$ \\ ${ }^{a}$ Mechanics and Materials Science Research Center, Ningbo University, Ningbo, Fenghua Road 818, China \\ ${ }^{\mathrm{b}}$ State Key Laboratory of Nonlinear Mechanics (LNM), Institute of Mechanics, Chinese Academy of Sciences, Beijing, Zhongguancun, China
}

\section{A R T I C L E I N F O}

\section{Article history:}

Received 11 July 2007

Accepted 27 May 2008

Available online 21 June 2008

\section{Keywords:}

B. Sulphate erosion

B. Ultrasonic technique

C. Microdamage evolution

C. Wave velocity

\begin{abstract}
A B S T R A C T
Ultrasonic technique is used to detect the velocity change of stress wave propagated in the cement mortar immersed in the solution of sodium sulfate for 425 days. Also the density change of specimens at different erosion time is measured. By curve fitting, the effect of solutions' concentration and water/cement ratio on the damage evolution is analyzed. The SEM observation on the growth of delayed ettringite is also performed. It shows that the damage evolution of specimens attacked by sulphate solution is dominantly induced by the nucleation and growth of delayed ettringite, and the average size of microvoids in cement mortar affects the damage evolution significantly.
\end{abstract}

(c) 2008 Elsevier Ltd. All rights reserved.

\section{Introduction}

Durability of concrete materials under attack of seawater is an important topic, and it attracts a lot of attentions in research. It is well known that the corrosion of reinforcing steel bars due to the attack of the chlorine ions $\left(\mathrm{Cl}^{1-}\right)$ in seawater leads to the decrease of the durability of reinforced concrete $(\mathrm{RC})$ in the seawater environment. Another eroding mechanism, namely, the erosion of sulfate, is still a challenging topic. In recent years, more attention has been paid to the corrosion of steel bars in concrete due to the attack of seawater. For instance, in experimental studies on the mechanism of corrosion of reinforced steel bars, Elsener calculated instantaneous values of corrosion rate of steel in concrete from the experimental date of polarization resistance [1]; Bertolini et al. investigated the effect of stray current on the corrosion behaviour of steel in concrete with considering both corrosion initiation and propagation [2]; furthermore, Choi et al. studied corrosion behaviour of steel bar embedded in concrete without fly ash and with fly ash under complete immersion in $3.5 \mathrm{wt}$.\% $\mathrm{NaCl}$ solution [3]; Kapat et al. presented the findings of an experimental investigation of potentiostatic study on reinforced steel in chloride contaminated concrete powder solution extracts [4]; Garcés et al. studied the effect of different carbonaceous materials, which are added to concrete mixes, on the corrosion of steel bars in concrete [5]; and Ouglova et al. dealt with elastic properties of iron oxides formed by corrosion in reinforced concrete structures [6]. In the studies for preventing corrosion of reinforced steel bars in concrete, Sawada et al. introduced two organic bases (ethanolamine and guani-

\footnotetext{
* Corresponding author. Tel.: +86 574 87600075; fax: +86 57487608358 .

E-mail address: chenjiankang@nbu.edu.cn (J.-k. Chen).
}

dine) to act as corrosion inhibitors for the steel bars [7]; Fajardo et al. studied electrochemical chloride extraction by means of cylindrical concrete specimens containing chlorides from "artificial" seawater [8]. In theoretical studies, Li and Page studied the model of chloride removal from concrete by an electrochemical method [9]; Srinivasan et al. proposed theoretical analysis method, i.e., neural network method to investigate the corrosion of steel in concrete [10]; Huet et al. dealt with the modeling of the cathodic reaction, which is the main mechanisms of steel rebar corrosion [11].

In fact, there are about $2800-3000 \mathrm{mg} \mathrm{SO}_{4}^{2-}$ ions per litre seawater, and if these ions get into concretes, they will be combined by the solution of calcium hydroxide to form solid ettringite, such an ettringite is called as delayed ettringite [12]. Usually, the nucleation and growth of the delayed ettringite occur in the microvoids in cement mortar materials [13-16]. If the delayed ettringite grows and touches to the boundary of the voids, it will produce an expansion force to the cement mortar materials. Under the action of the expansion force, the nucleation and growth of microcracks will also occur in concretes. The microcrack evolution may lead to $\mathrm{Cl}^{-}$filter concretes more easily, and this will result in the much quick corrosion of the reinforced steel bar. In other words, if the concrete is considered as matrix material, sulfate will erode matrix, whereas chlorate will attack reinforcing phase. Because those two types of erosion are coupled, the mechanism for the decrease of durability of RC materials is actually very complex.

In this paper, close attention is given to the damage evolution in concretes attacked by sulfate in seawater. Because the density of carpolites in concretes is much higher than that of cement mortar, there is hardly any solution of calcium hydroxide inside of them, those carpolites can hardly be eroded by sulfate. In other words, the damage evolution induced by the delayed ettringite can only 
take place in cement mortar or at the interface between the cement mortar and carpolites. Therefore, the specimens of cement mortar are taken to study the damage evolution due to the attack of seawater. As pointed out by Burstein et al., the processes of damage evolution include the nucleation and growth of microdamage [17]. The evolution of microdamage will affect the strength, the modulus of elasticity, the Poisson's ratio, the toughness of cement mortar [18-23], and that implies it is possible to separate damage evolution from the variation of those macro-properties, such as from the variation of the modulus. The modulus of a specimen can be determined by the velocity of stress wave propagated in the material and the density of the specimen [24], hence, the testing technique of ultrasonic sound is employed for measuring the variation of the velocity of the ultrasonic waves at different eroding time.

Firstly, specimens of cement mortar with water/cement ratio $(W / C)$ of $0.4,0.6,0.7$, and 0.8 are formed. Usually, different water/cement ratio leads to different average size of microvoids in specimens. Therefore, the size effect of microvoids on the damage evolution may be studied by investigating the influence of different value of $W / C$. Secondly, the solution of sodium sulfate is used to simulate seawater, because the erosion of seawater to the cement mortar is dominantly the erosion of $\mathrm{SO}_{4}^{2-}$ ions. In order to obtain the experimental results more quickly, the concentration of the solution of sodium sulfate is much higher than that of seawater. The specimens are put into the solution of sodium sulfate with concentration of $8 \%(54,000 \mathrm{ppm}), 3 \%(20,250 \mathrm{ppm})$, and $0 \%$ (water, it was used for reference). Each specimen is tested 16 times by means of ultrasonic sound within 425 days with different time interval, and comprehensive experimental results are obtained. Meanwhile, the growth of delayed ettringite in a small specimen is observed through SEM observations. Thirdly, a function with two parameters is proposed to describe the damage evolution, the parameters are determined by curve fitting. Finally, the effect of water/cement ratio (or average size of microvoids) on the damage evolution is discussed. Experimental results show that the influence of average size of microvoids on the damage evolution is significant.

\section{Experimental}

\subsection{Specimen}

The No. 425 cement (GB/175-1999) is chosen as specimen material. This kind of cement consists of $13.01 \mathrm{wt} . \% \mathrm{Al}_{2} \mathrm{O}_{3}$, $2.63 \mathrm{wt} . \% \mathrm{SO}_{3}$, and $2.91 \mathrm{wt} . \% \mathrm{Fe}_{2} \mathrm{O}_{3}$. The size of the specimens is $0.15 \times 0.15 \times 0.15 \mathrm{~m}^{3}$. The water/cement ratio, of the specimens, $W / C$, is chosen as $0.4,0.6,0.7$, and 0.8 .

\subsection{Ultrasonic test}

Three types of solution are prepared for the erosion experiment. One is water, and it is used for comparison. Others are solutions of sodium sulfate with concentrations of $3 \%$ $(20,250 \mathrm{ppm})$, and $8 \%(54,000 \mathrm{ppm})$, respectively, and they are used to simulate the sulfate in seawater. The specimens are immersed in the solutions up to 425 days (shown in Fig. 1). From Fig. 2 we can see that macro-morphology cement mortar at different erosion time is changed. Meanwhile, the specimens are tested with ultrasonic waves with different time interval. The variety of the velocity of ultrasonic waves propagated in the specimens, as well as the change of the density of the specimens are all plotted in Figs. 3-8. It should be pointed out that when the eroding time reaches to 425 days, the specimens almost lose their strength.

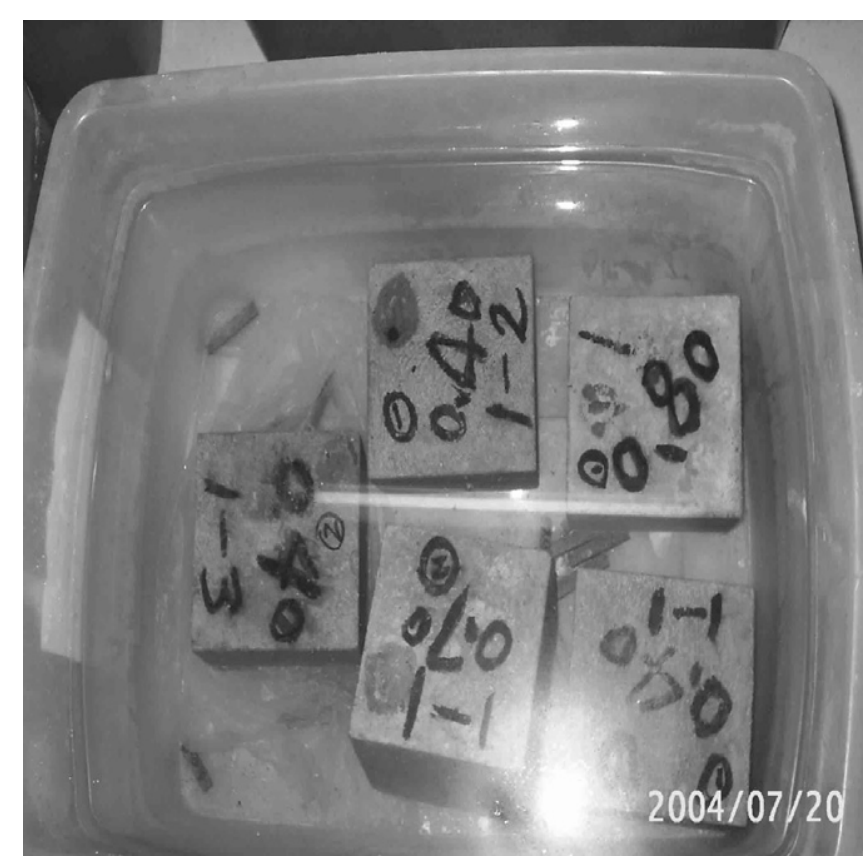

Fig. 1. Specimens are immersed in sulphate solution.

\subsection{SEM observation}

A small specimen of cement is formed and stored in the solution of sodium sulfate to observe the growth of delayed ettringite with SEM. The SEM image of ettringite for the specimen immersed in the solution of sulfate for 7 days is shown in Fig. 9.

\section{Analysis of experimental results}

Cement mortar materials are actually viscoelastic ones due to the existence of the $\mathrm{C}-\mathrm{S}-\mathrm{H}$ gel in these materials. The viscosity of the materials results in the attenuation of amplitude of an ultrasonic wave and the dispersion of the wave shape, but it dose not affect the wave velocity. The damage evolution, however, will affect the wave velocity. Therefore, from the decrease magnitude of wave velocity as well as the variation of density of specimens, we can evaluate the damage in materials.

From the results given in Figs. 3-8 we can see that both the wave velocity and the density vary with erosion time. That implies that the modulus of cement mortar is not a constant, but a function of erosion time.

Because a specimen is cubic, and the incident wave locates at one point of surface of the specimen, therefore, the wave propagated in the specimen can be approximately treated as a longitudinal wave. The relation among the wave velocity $c$, the density $\rho$, and the modulus $E$ has been given as [24]

$c=\sqrt{\frac{E}{\rho} \cdot \frac{1-v}{(1-2 v)(1+v)}}$

where $v$ is the Poisson's ratio of materials.

Because $c$ and $\rho$ are all functions of erosion time, obviously, $E$ is a function of erosion time, too. Assume the modulus may be written as

$E=E_{0} \eta(t)$

where $E_{0}$ is the initial modulus, and $\eta(t)$ is a coefficient related to the damage evolution in materials, and it satisfies

$\eta(t) \geqslant 0$ 


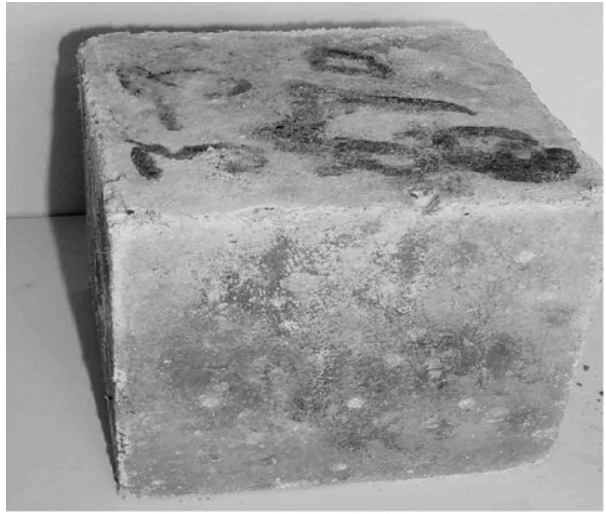

a. Immersed for 135days

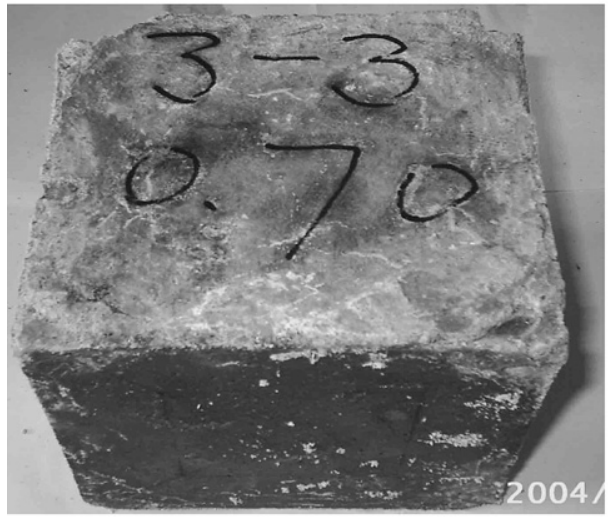

c. Immersed for 345 days

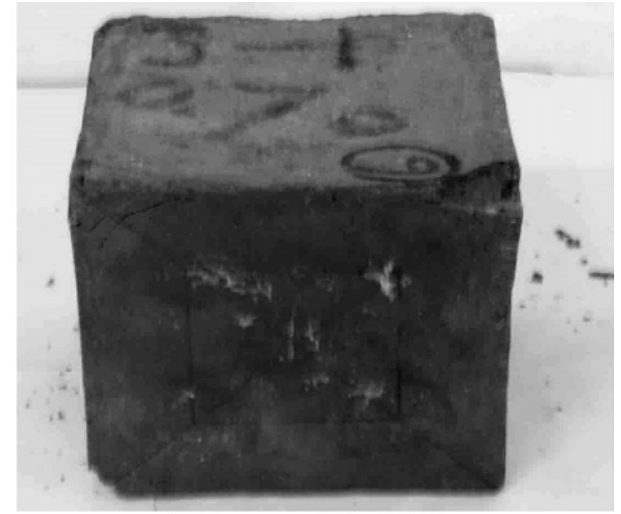

b. Immersed for 225 days

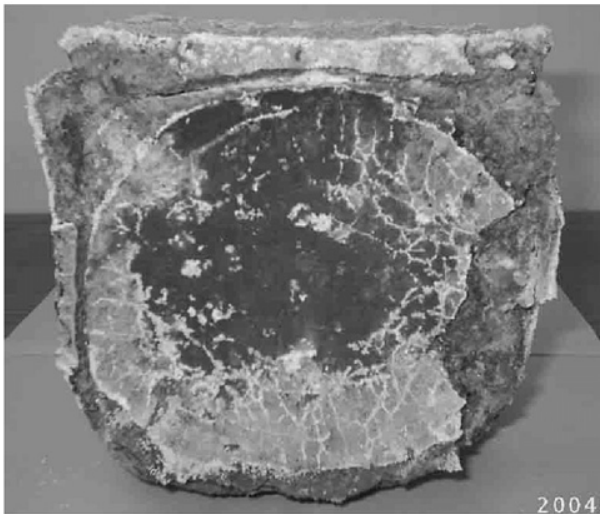

d. Immersed for 425 days

Fig. 2. Evolution of macro, morphologies of corrosion of cement mortar immersed in sodium sulfate with concentration $8 \%$.

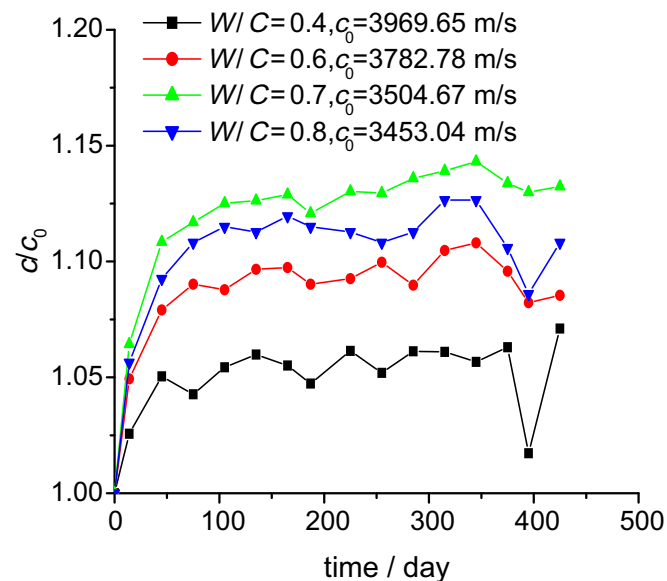

Fig. 3. Wave velocity of specimens immersed in water.

Substitution of Eq. (2) into Eq. (1) yields

$\eta(t)=\frac{c^{2}(t)}{E_{0}} \rho(t) \frac{(1-2 v)(1+v)}{1-v}$

The coefficient $\eta(t)$ can be determined by substituting the numerical results in Figs. 3-8 into Eq. (3). The curves of $\eta(t)$ against $t$ are shown in Figs. 10-12.

Let us consider now what kinds of factor will affect the value of $\eta(t)$.

The first factor is the continuous hydration processes. After the specimens immersed in solutions, the hydration processes do not stop. This continuous hydration processes may lead to the increase

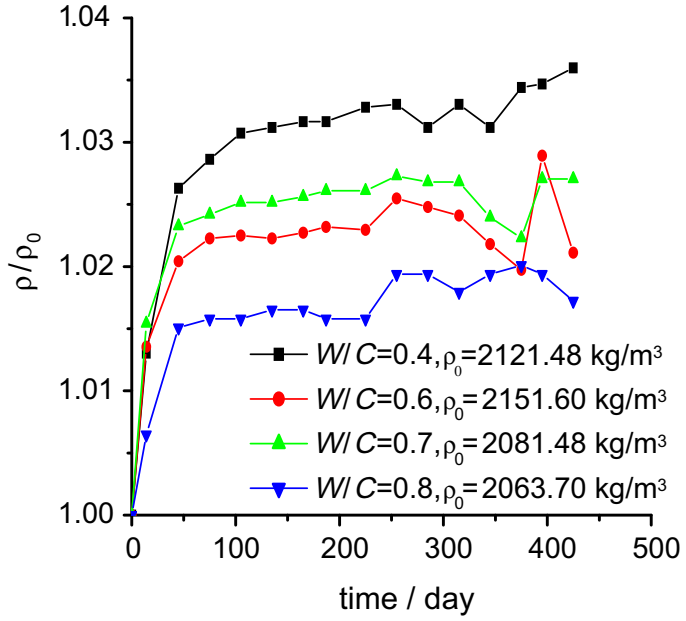

Fig. 4. Density of specimens immersed in water.

of $\eta(t)$. This factor is denoted by $f_{H}(t)$ which may be determined in terms of the experimental results of specimens immersed in water.

The second factor is the nucleation and growth of delayed ettringite in specimens. Those delayed ettringite looks like short reinforced fibers, and it may also leads to the increases the value of $\eta(t)$. This factor is expressed by $f_{E}(t)$.

The third factor is the damage evolution due to the expansion force caused by delayed ettringite, and this factor is described by $D(t)$ which may lead to the decrease of modulus of specimen. 


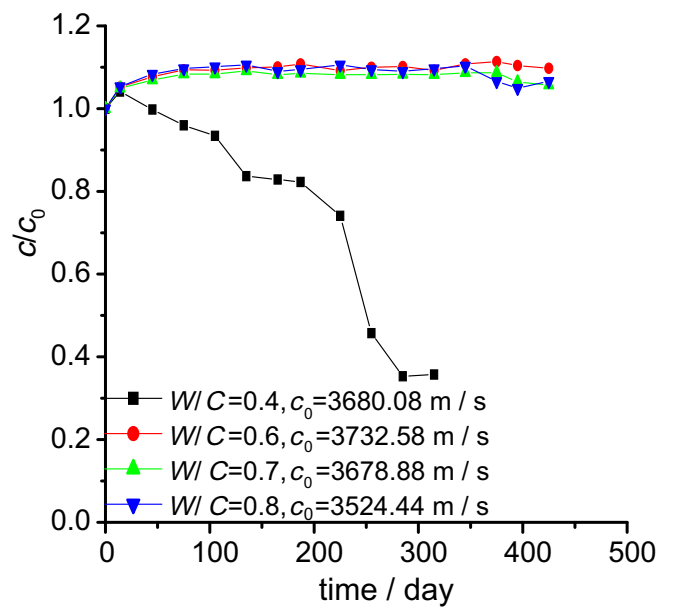

Fig. 5. Wave velocity of specimens immersed in solution of sodium sulfate with concentration of $3 \%$.

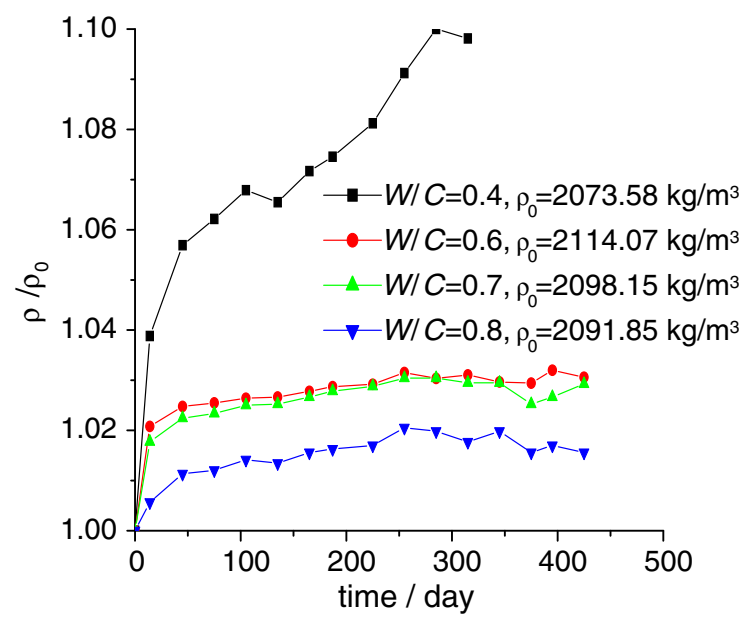

Fig. 6. Density of specimens immersed in solution of sodium sulfate with concentration of $3 \%$.

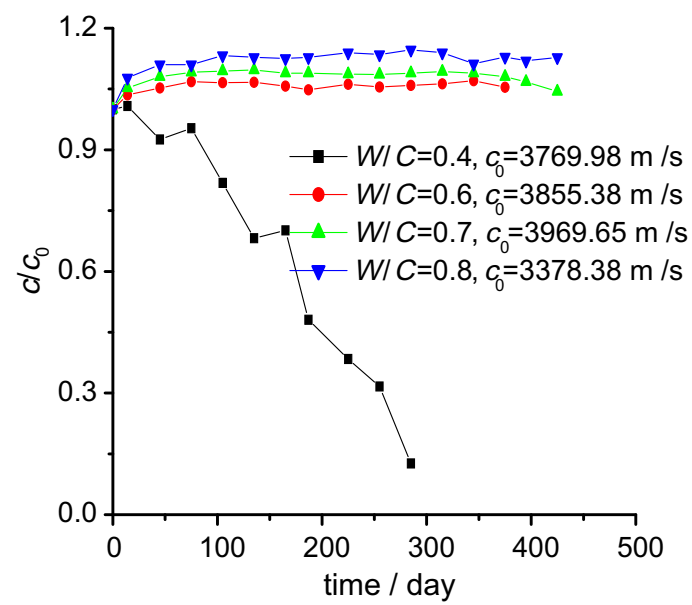

Fig. 7. Wave velocity of the specimens immersed in solution of sodium sulfate with concentration of $8 \%$.

According to the above analysis, $\eta(t)$ may be written as $\eta(t)=\left[f_{H}(t)+f_{E}(t)\right] \cdot[1-D(t)]$

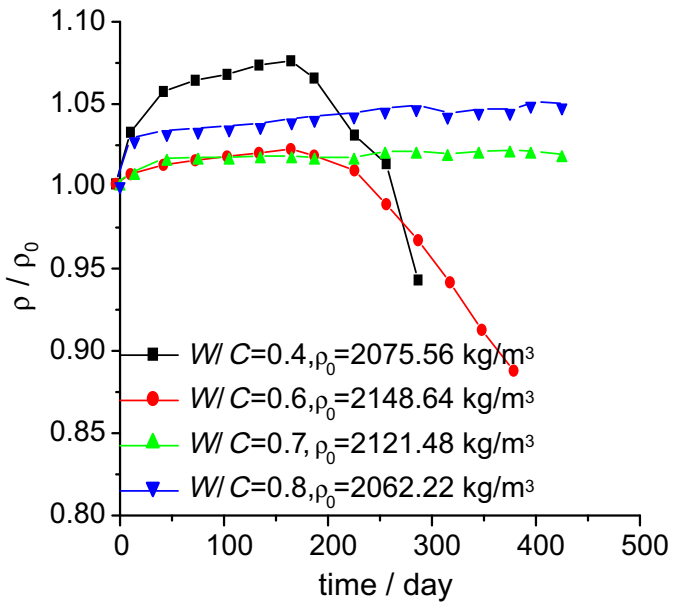

Fig. 8. Density of specimens immersed in solution of sodium sulfate with concentration of $8 \%$.

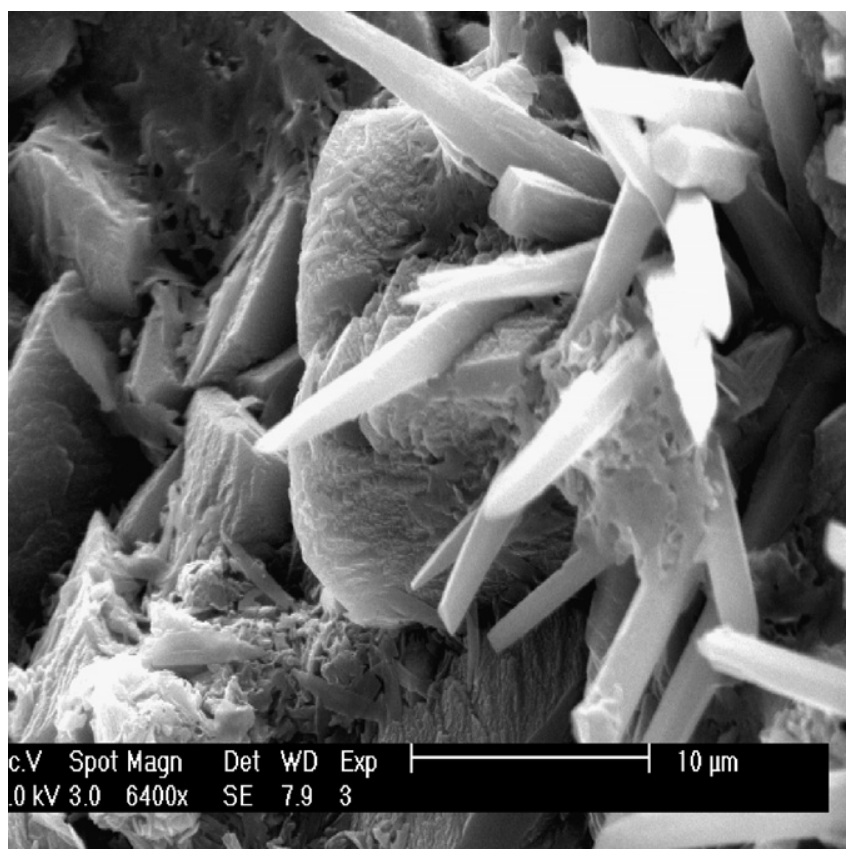

Fig. 9. SEM photo of ettringite growth in cement specimen immersed in the solution of sodium sulfate for 7 days.

where $f_{H}(t)$ will be determined in terms of the dates in Fig. 8, whereas $f_{E}(t)$, and $D(t)$ are determined by the results given in Figs. 9 and 10 . It is obvious that $f_{H}(t), f_{E}(t)$, and $D(t)$ must satisfy the following conditions:

$$
\begin{gathered}
f_{H}(t) \geqslant 1, \quad f_{H}(0)=1 \\
f_{E}(t) \geqslant 0, \quad f_{E}(0)=0 \\
D(0)=0 \quad\left(0 \leqslant t \leqslant t_{c r}\right) \\
D(t) \leqslant f_{H}(t)+f_{E}(t)
\end{gathered}
$$

According to Eq. (5), we assume

$$
\begin{aligned}
f_{H}(t) & =\frac{1}{1-a_{H} \cdot\left[1-\exp \left(-b_{H} \frac{t}{t_{0}}\right)\right]} \\
f_{E}(t) & =a_{E} \cdot\left[1-\exp \left(-b_{E} \frac{t}{t_{0}}\right)\right] \\
D(t) & =a_{D} \cdot\left(\frac{t}{t_{0}}\right)^{b_{D}}
\end{aligned}
$$




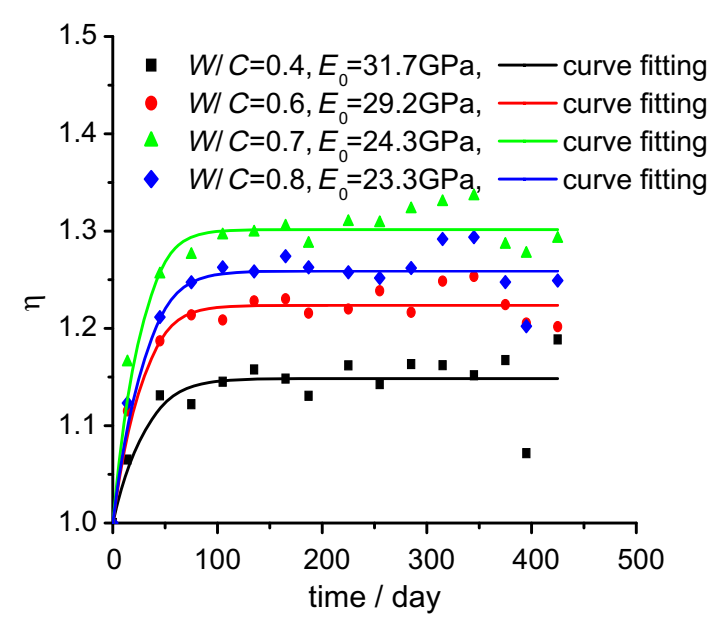

Fig. 10. Coefficient of modulus of specimens immersed in water.

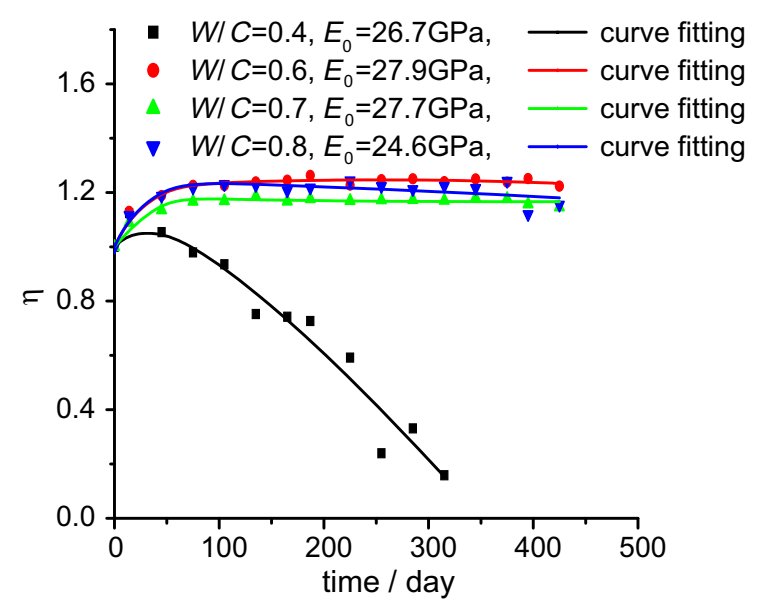

Fig. 11. Coefficient of modulus of specimen immersed in solution of sodium sulfate with concentration of $3 \%$.

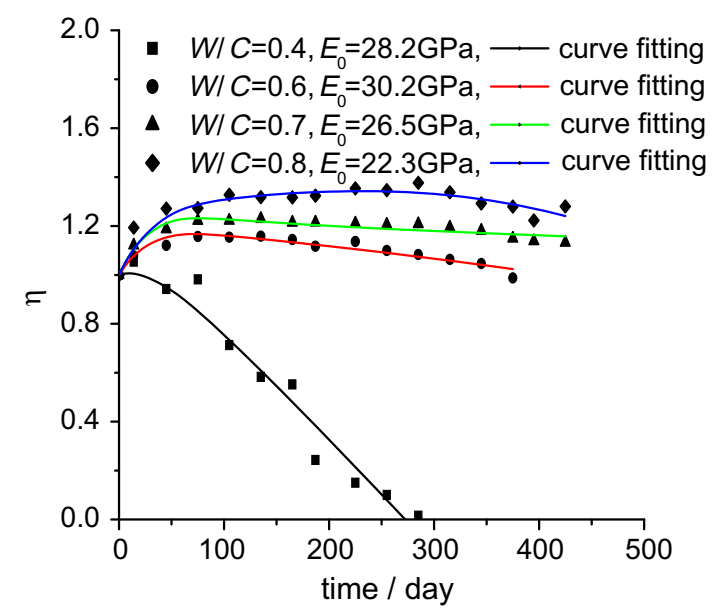

Fig. 12. Coefficient of modulus of specimens immersed in solution of sodium sulfate with concentration of $8 \%$.

where $t_{0}=730$ days (2 years), non-dimensional parameters $a_{H}, b_{H}$, $a_{E}, b_{E}, a_{D}$, and $b_{D}$ will be determined by simulating the dates in Figs.
$8-10$. The fitted curves are also shown in Figs. 8-10. From those curves we can see that the functions described in Eqs. (6)-(8) are acceptable.

Because the failure of the specimens attacked by seawater is induced by the damage evolution, we will pay close attention to the effect of water/cement ratio on the damage evolution. The values of parameters are listed in Table 1 and 2. The curves of damage function are plotted in Figs. 13 and 14.

From the Tables 1 and 2 we can see that $f_{E}(t)$ is dominantly affected by water-cement value, $W / C$. The damage, $D(t)$, however, depends not only on the $W / C$, but also on the concentration of sulfate solution. Because the decrease of the durability of cement is induced by the damage evolution, we will pay close attention to the evolution of $D(t)$. The curves of $D$ against erosion time, $t$, are plotted in Figs. 13 and 14. The results given in Figs. 13 and 14 indicate that the damage evolution in the specimens with $W / C=0.4$ is more rapid than that in other specimens, and this conclusion should be noticed. Usually, people tend to decrease the value of $W / C$ (or decrease the size of microivoids) for improving the durability of concrete materials, but our experimental results do not support this practice. We will give the further explanation about this conclusion below.

In the environment of seawater, the expansion force induced by the delayed ettringite will lead to the appearance of microdamage in cement mortar. The nucleation of delayed ettringite usually takes place in the corner of voids in cement mortar, and then it grows along the direction of its crystal axis. When the tip of a delayed ettringite touches the boundary of voids, it will apply contact force at the surface of a void. Under the action of the contact force, the maximum principal stress at the surface of the void is tensile stress, hence, the microcracks will appear due to the tensile stress.

Generally, the different $W / C$ may lead to different size of microvoids within cement mortar, therefore, the effect of $W / C$ on damage evolution is equivalent to the effect of average size of microvoids. For the cement mortar with high $W / C$, the average size of microvoids is large. This means longer time is needed for the delayed ettringite to reach the boundary of the void, and this may delay the appearance of damage. On the other hand, the tensile strength of the cement mortar with larger $W / C$ is lower, once the delayed ettringite touches the boundary of void, the microcrack will expand rapidly. Therefore, the damage evolution depends not only on the size of microvoids, but also on the tensile strength of cement mortar. The fitted results shown in Figs. 13 and 14 indicate that there is a competition mechanism for the durability of cement mortar. For the cement mortar with small voids, sulfate infiltrates the material slowly, and this may lead to the lower damage evolution. On the other hand, for small voids, the tip of the delayed ettringite will reach the interface between the matrix and the void earlier, and it may lead to more rapid damage evolution. Therefore, in order to improve the durability of cement mortar, both the void size and the tensile strength of the material should be taken into account.

Table 1

Fitting results of parameters for the $3 \%$ concentration of sulfate solution

\begin{tabular}{|c|c|c|c|c|c|c|}
\hline \multirow[t]{2}{*}{$W / C$} & \multicolumn{6}{|c|}{ Parameters } \\
\hline & $a_{H}$ & $b_{H}$ & $a_{E}$ & $b_{E}$ & $a_{D}$ & $b_{D}$ \\
\hline 0.4 & 0.1293 & 31.73 & 0.1589 & 2.999 & 2.418 & 1.204 \\
\hline 0.6 & 0.1828 & 38.14 & 8.5 & 0.0809 & 0.3912 & 0.9338 \\
\hline 0.7 & 0.2317 & 42.73 & 1.085 & 0.3443 & 0.2627 & 0.3469 \\
\hline 0.8 & 0.2057 & 35.42 & 9.122 & 0.04591 & 0.3397 & 0.8646 \\
\hline
\end{tabular}


Table 2

Fitting results of parameters for the $8 \%$ concentration of sulfate solution

\begin{tabular}{lllllll}
\hline W/C & \multicolumn{7}{l}{ Parameters } & \multicolumn{6}{l}{$l$} \\
\cline { 2 - 7 } & $a_{H}$ & $b_{H}$ & $a_{E}$ & $b_{E}$ & $a_{D}$ & $b_{D}$ \\
\hline 0.4 & 0.1293 & 31.73 & 0.1589 & 2.999 & 2.656 & 0.9912 \\
0.6 & 0.1828 & 38.14 & 8.5 & 0.0809 & 0.6017 & 0.822 \\
0.7 & 0.2317 & 42.73 & 1.085 & 0.3443 & 0.3284 & 0.6553 \\
0.8 & 0.2057 & 35.42 & 9.122 & 0.04591 & 0.7298 & 2.664 \\
\hline
\end{tabular}

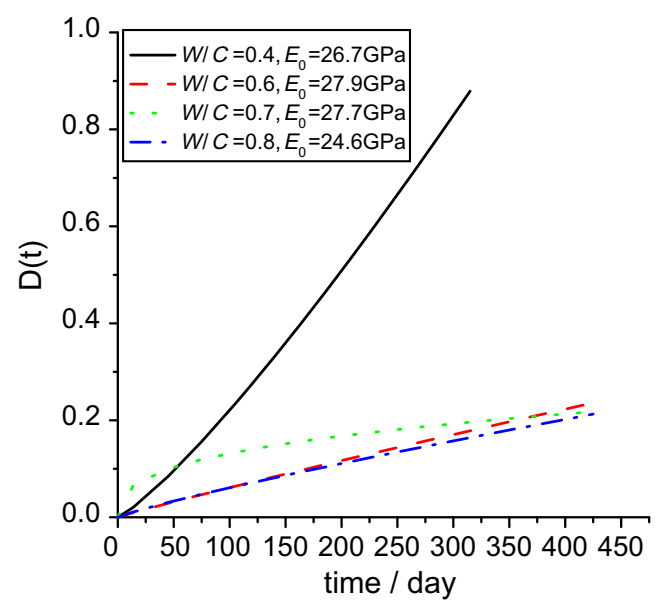

Fig. 13. Damage evolution in specimens immersed in sodium sulfate solution with concentration of $3 \%$.

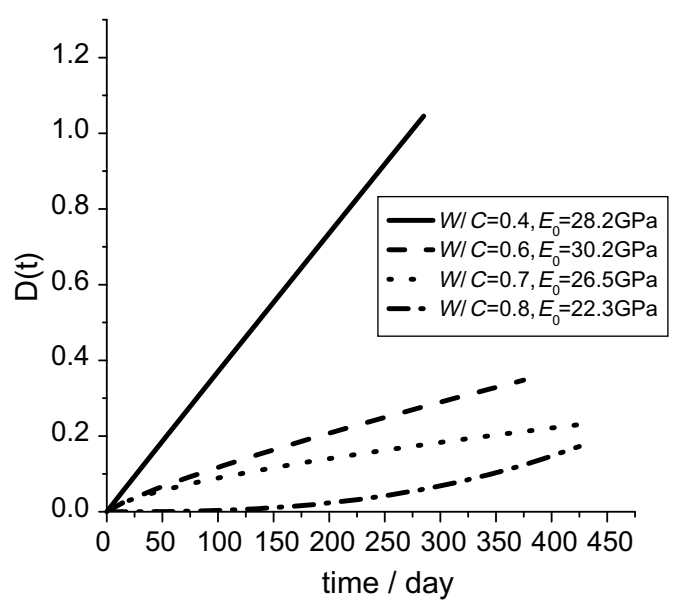

Fig. 14. Damage evolution in specimens immersed in sodium sulfate solution with concentration of $8 \%$.

\section{Conclusions}

Corrosion of cement mortar due to attack of sulphate in seawater may be roughly divided to two stages. One stage is the voids in cement mortar are filled by delayed ettringite, and this may lead to increase of modulus of cement mortar. In this stage, the wave velocity of ultrasonic sound speeds up. The other stage is decrease of modulus. Because the action of delayed ettringite, microdamage evolution may take place in this stage, and the wave velocity of ultrasonic sound will slow down, and the modulus of cement mortar decreases. The numerical results show that the damage evolution depends strongly on the value of $W / C$ and the concentration of solutions of sodium sulfate. There is a competition mechanism for damage evolution. The corrosion of cement mortar with small voids is not always less than that of cement mortar with large voids. In order to improve the durability of concrete in ocean environment, both the void size and the tensile strength of concrete should be taken into account.

\section{Acknowledgements}

The financial support by the National Natural Science Foundation of China (NSFC) under the Grant No. 10572064, the Natural Science Foundation of Zhejiang Province (\#Y107780) and K.C. Wong Magna Fund in Ningbo University is acknowledgement. The first author thanks Professors Wang Ji and Professor Yang Liming of Ningbo University for stimulating discussions.

\section{References}

[1] B. Elsener, Corrosion rate of steel in concrete-Measurements beyond the Tafel law, Corrosion Science 47 (2005) 3019-3033.

[2] L. Bertolini, M. Carsana, P. Pedeferri, Corrosion behaviour of steel in concrete in the presence of stray current, Corrosion Science 49 (2007) 1056-1068.

[3] Y. Choi, J. Kim, K. Lee, Corrosion behaviour of steel bar embedded in fly ash concrete, Corrosion Science 48 (2006) 1733-1745.

[4] C. Kapat, B. Pradhan, B. Bhattacharjee, Potentiostatic study of reinforcing steel in chloride contaminated concrete powder solution extracts, Corrosion Science 48 (2006) 1757-1769.

[5] P. Garcés, L. Andión, I. Varga, G. Catalá, E. Zornoza, Corrosion of steel reinforcement in structural concrete with carbon material addition, Corrosion Science 49 (2007) 2557-2566.

[6] A. Ouglova, Y. Berthaud, M. Francois, F. Foct, Mechanical properties of an iron oxide formed by corrosion in reinforced concrete structures, Corrosion Science 48 (2006) 3988-4000.

[7] S. Sawada, C.L. Page, M.M. Page, Electrochemical injection of organic corrosion inhibitors into concrete, Corrosion Science 47 (2005) 2063-2078.

[8] G. Fajardo, G. Escadeillas, G. Arliguie, Electrochemical chloride extraction (ECE) from steel-reinforced concrete specimens contaminated by "artificial" seawater, Corrosion Science 48 (2006) 110-125.

[9] L.Y. Li, C.L. Page, Finite element modelling of chloride removal from concrete by an electrochemical method, Corrosion Science 42 (2000) 2145-2165.

[10] T. Parthiban, R. Ravi, G.T. Parthiban, S. Srinivasan, K.R. Ramakrishnan, M. Raghavan, Neural network analysis for corrosion of steel in concrete, Corrosion Science 47 (2005) 1625-1642.

[11] B. Huet, V. L'hostis, G. Santarini, D. Feron, H. Idrissi, Steel corrosion in concrete: Determinist modeling of cathodic reaction as a function of water saturation degree, Corrosion Science 49 (2007) 1918-1932.

[12] Zhu Hongjun, Cheng Haili, Jiang Demin, Special Concretes and New Type Concretes, VCH, 2004.

[13] M. Santhanam, M.D. Cohen, J. Olek, Mechanism of sulfate attack: A fresh look Part 1: Summary of experimental results, Cement and Concrete Research 32 (2002) 915-921.

[14] M. Santhanam, M.D. Cohen, J. Olek, Mechanism of sulfate attack: A fresh look Part 2: Proposed mechanisms, Cement and Concrete Research 33 (2003) 341346.

[15] S.U. Dulaijan, M. Maslehuddin, Sulfate resistance of plain and blended cements exposed to varying concentrations of sodium sulfate, Cement and Concrete Composites 25 (2003) 429-437.

[16] S.T. Lee, H.Y. Moon, R.N. Swamy, Sulfate attack and role of silica fume in resisting strength loss, Cement and Concrete Composites 27 (2005) 65-76.

[17] G.T. Burstein, P.C. Pistorius, S.P. Mattin, The nucleation and growth of corrosion pits on stainless steel, Corrosion Science 35 (1993) 57-62.

[18] A.M. Cody, H. Lee, R.D. Cody, P.G. Spry, The effects of chemical environment on the nucleation, growth, and stability of ettringite $\left[\mathrm{Ca}_{3} \mathrm{Al}(\mathrm{OH})_{6}\right]_{2}\left(\mathrm{SO}_{4}\right)_{32} 6 \mathrm{H}_{2} \mathrm{O}$, Cement and Concrete Research 34 (2004) 869-889.

[19] B. Mather, Sulfate soundness, sulfate attack and expansive cement in concrete, in: Proceedings, RILEM International Symposium on Concrete Durability, Tech. Univ. Prague, 1969, 209-220.

[20] M.Q. Jiang, J.K. Chen, D.Y. Yang, Dynamic modulus of cement mortar in sulfate erosion measured by ultrasonic checking, Journal of the Chinese Ceramic Society 33 (2005) 126-132.

[21] P.K. Metha, Expansion of ettringite by water absorption, Cement and Concrete Research 12 (1982) 121-122.

[22] A.B. Yimaz, B. Yazici, M. Erbil, The effect of sulphate ion on concrete and reinforced concrete, Cement and Concrete Research 27 (1997) 1271-1279.

[23] K.L. Serivener, H.F. Taylor, Delayed ettringite formation. A microstructural and microanalytical study, Advanced Cement Research 5 (1993) 139-146.

[24] M.A. Meyers, Dynamic Behavior of Materials, John Wiley \& Sons, Inc., New York, 1994 